\title{
UNUSUAL DETECTION OF TUBERCULOSIS IN A WOMAN WITH DOWN'S SYNDROME
}

\author{
Pešut DP, ${ }^{1,2 *}$ Raljević S, ${ }^{2}$ Slijepčević Tomić $\mathrm{Lj}^{2,3}$
}

*Corresponding Author: Dragica P. Pešut, School of Medicine University of Belgrade, Clinical Centre of Serbia, Institute of Lung Disease and Tuberculosis, Research and Epidemiology Department, 11000 Belgrade, Visegradska 26, Serbia; Tel.: +381-11-3615561; Fax: +381-112681591; E-mail: dragica.pesut@ gmail.com

\begin{abstract}
A woman with Down's syndrome (DS) had subfebrile temperature, nodular/patchy shadows on the chest X-ray over the right pulmonary base, and a history of recurrent respiratory infections. She was pale, asthenic, uncommunicative, mildly anemic and the erythrocyte sedimentation rate was 80 /first hour. The tuberculin skin test (TST) $\mathrm{PPD}_{3}$ was negative. Mycobacterium tuberculosis was isolated from oral mucosal brushing, sensitive to the first line anti-tuberculosis drugs. Patients with DS and other mental disabilities need special care and attention during diagnostic procedures for tuberculosis (TB).
\end{abstract}

Key words: Diagnosis, Down's syndrome (DS), Trisomy 21, Tuberculosis (TB).

School of Medicine University of Belgrade, Internal Medicine Department, Belgrade, Serbia

2 Clinical Centre of Serbia, Institute of Lung Diseases and Tuberculosis, Research and Epidemiology Department, Belgrade, Serbia

3 National Reference Mycobacterial Laboratory, Belgrade, Serbia

\section{INTRODUCTION}

Down's syndrome (DS) or trisomy 21 is the most frequently identified cause of mental disability $[1,2]$. Individuals with DS differ considerably in language and communication skills. Down's syndrome is often associated with some impairment of cognitive ability, physical growth and a typical facial appearance [1-3]. The trisomy is a risk factor for several diseases such as congenital heart disease and leukemia, premature aging and recurrent infections, especially pulmonary infections, because of impaired cellular immunity [3-6]. Immunological investigation of a small number of DS patients with tuberculosis (TB) has shown no consistent defect [7]. The immune cellular status in children with DS is similar to that of the normal population as far as white blood cell, lymphocyte, CD4(+), CD8(+), natural killer and immunoglobulins are concerned [8], and maturation of $\mathrm{T}$ lymphocytes may be impaired in healthy young individuals with DS [9]. Although common, illness in people with intellectual disabilities may be under diagnosed and poorly managed [10]. The life expectancy for people with DS has increased substantially so that it is now common for a person with DS to live to age 50 years and beyond $[1,3]$. 


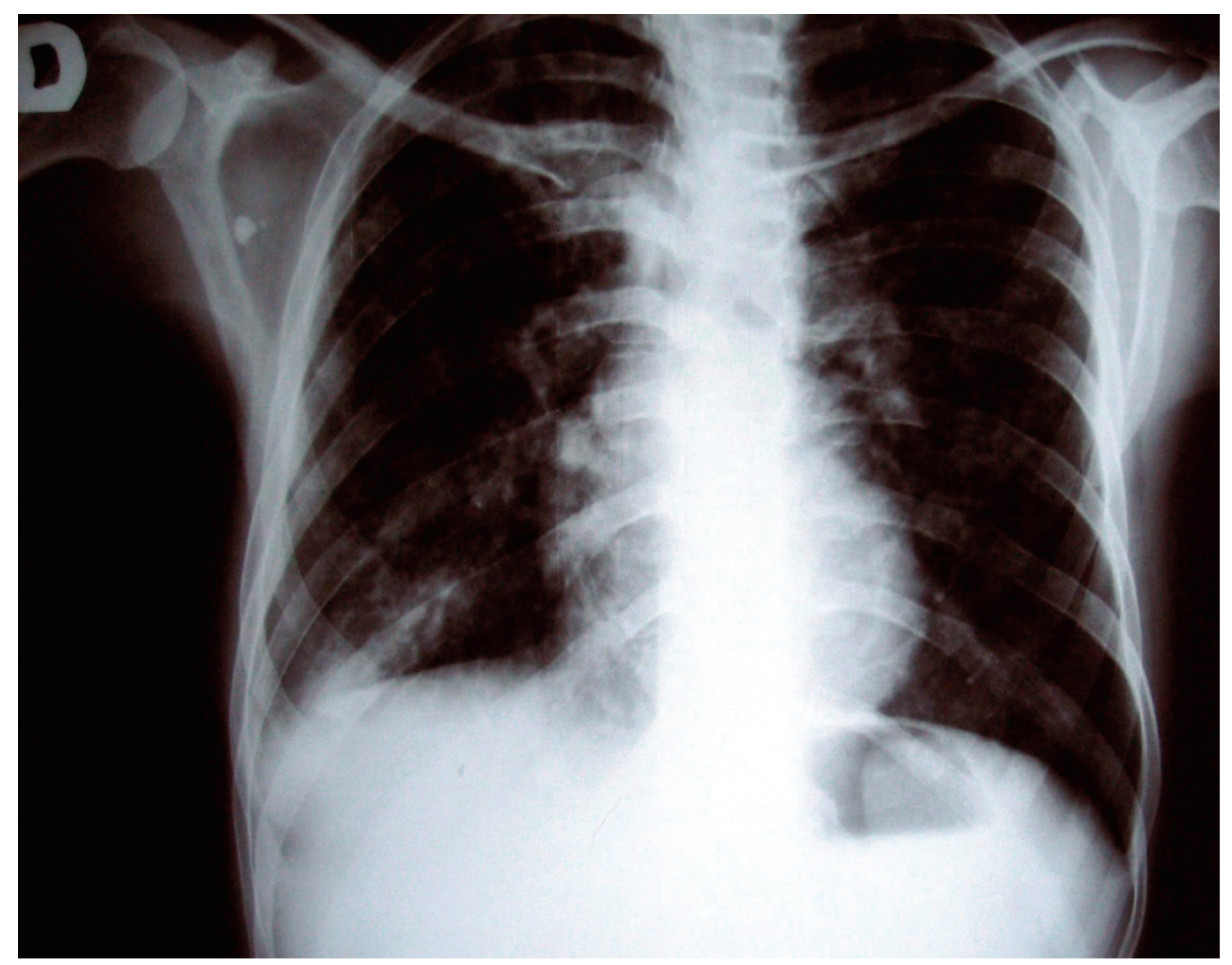

Figure 1. Standard postero-anterior chest x-ray of a 37-year-old female patient with Down's syndrome. Calcified opacities, especially in both hilar and right axillary regions are suggestive of pulmonary and extrapulmonary tuberculosis sequelae

Tuberculosis is an infectious, treatable, and potentially lethal disease caused by the Mycobacterium tuberculosis (M. tuberculosis, M. bovis and M. africanum) complex. It usually affects lungs, but TB bacilli can spread to other sites, leading to extrapulmonary TB, especially in immune deficient persons. Few cases of TB in patients with DS have been reported but all reflected extrapulmonary disease with rare or severe complications [11-14]. The greatest single risk factor for developing active TB in an infected person is concurrent infection with human immune deficiency virus (HIV) $[15,16]$. Sputum smear microscopy can document Mycobacteria and a positive culture result for M. tuberculosis is the golden diagnostic standard in TB. Isolation of the bacillus makes it possible to perform drug resistance testing.

Case Report. A 37-year-old woman with DS was admitted to the Pulmonology Department. Despite antibiotic therapy, she had a subfebrile tempe- rature of 2-month duration, and nodular and patchy shadows over the right pulmonary base (Figure 1). She had a history of recurrent upper and lower respiratory tract infections and no history of TB. She received the BCG (bacille Calmette Guerin) vaccination at birth.

She was without cough, pale, asthenic, of subaverage height, upset, frightened, uncommunicative and with signs of dementia. She had a speech disability and looked like a person with accelerated aging. The erythrocyte sedimentation rate was $80 \mathrm{~mm} /$ first hour. She was mildly anemic and HIV-seronegative. The lungs were clear to auscultation. Besides nodular and patchy shadows on the right lower pulmonary lobe, the chest X-ray showed calcification in bronchopulmonary lymph nodes bilaterally, especially in the right pulmonary hilar region, and a calcified $7 \times 4 \mathrm{~mm}$ density in the right axillary lymph nodes (Figure 1). The latter suggested a previous hematogenous dissemination that occurred most prob- 
ably during primary $\mathrm{TB}$. The tuberculin skin test (TST) $\mathrm{PPD}_{3}$ was negative.

It was not possible to obtain a sputum sample for bacteriological examination. Apart from the standard bacteriological analysis, an oral brushing sample was taken for acid fast bacilli (the result was negative) and the material was cultured on Lowenstein-Jenssen medium.

Before the culture result confirmed $M$. tuberculosis, we established a diagnosis of TB on the basis of: 1) the patient's history, 2) clinical features, 3) radiographic changes suggestive to previous (disseminated) $\mathrm{TB}, 4$ ) the presence of TB risk factors such as stress and malnutrition, and 5) belonging to a risk group for developing TB from home in an intermediate TB incidence country $[17,18]$. Treatment was initiated following a standardized anti-tuberculosis drug regimen. She became afebrile very soon and started to gain weight. Positive culture results of oral mucosa brushing for $M$. tuberculosis confirmed the diagnosis of TB. The bacillus was sensitive to all the first-line anti-tuberculosis drugs tested.

\section{DISCUSSION}

An adult female patient with DS suspected of having active pulmonary TB was unable to produce sputum, which made the diagnosis of pulmonary TB difficult. She was too upset and frightened to cooperate successfully, unable to understand and undergo procedures like sputum induction, gastric lavage or bronchoscopy, thus we applied an unusual procedure like oral cavity brushing to obtain the material and to confirm M. tuberculosis. A hospital-based study has compared sputum obtained by nasopharyngeal aspiration and by sputum induction for staining and culturing of M. tuberculosis [19]. In comparison, oral cavity brushing is less aggressive than the former but proved to be fully effective in our patient. Despite the fact that it was beneficial in the case of DS, we may not recommend oral cavity brushing instead of established routine clinical procedures of sputum examination for the detection of pulmonary TB. However, the method is suitable for patients who are not able to cooperate or to undergo usual diagnostic procedures.

Premature aging is a characteristic of adults with DS. Dementia, or memory loss and impaired judgment similar to that of Alzheimer disease patients, may appear in adults with DS and occurs before the person is 40 years old [3]. Both occurred in our patient.

There was no history of TB in the patient's medical file. However, besides a mass primary complex, the chest X-ray showed right axillary lymph node indicative of TB sequelae expected from previous extrapulmonary spreading of TB. The BCG vaccination at birth may have proved a protective effect in our patient [21].

Spreading of the TB infection also may occur in sputum-smear negative patients with pulmonary $\mathrm{TB}$, which is an important public health issue [22]. Tuberculosis control depends on successful diagnosis and treatment of active disease [23] and on drug sensitivity testing [24].

\section{CONCLUSIONS}

Patients with DS and mental disabilities need special attention and care during diagnostic procedures for TB. An unusual approach may be necessary to avoid the patient's discomfort or panic reaction, especially when communication is difficult. Population awareness of TB symptoms and clinicians' continual education of the risk factors for developing TB enable early detection of the disease. Early therapy contributes to better disease outcome and decreases the risk of spreading the TB infection within a community.

\section{REFERENCES}

1. Roper RJ, Reeves RH. Understanding the basis for Down syndrome phenotypes. PLoS Genet 2006; 2(3): e50.

2. Yang Q, Rasmussen SA, Friedman JM. Mortality associated with Down's syndrome in the USA from 1983 to 1997: a population-based study. Lancet 2002; 359 (9311): 1019-1025.

3. Centers for Disease Control. Morbidity and Mortality Weekly Report. 2006; 54(51\&52): 13011305.

4. Huang T, Watt H, Wald N, Morris J, Mutton D, Alberman E, Kelekun C. Birth prevalence of Down's syndrome in England and Wales 1990 to 1997. J Med Screen 1998; 5(4): 213-214.

5. Ferencz C, Neill CA, Boughman JA, Rubin JD, Brenner JI, Perry LW. Congenital cardiovascu- 
lar malformations associated with chromosome abnormalities: an epidemiologic study. J Pediatr 1989; 114(1): 79-86.

6. Yla-Herttuala S, Luoma J, Nikkari T, Kivimaki T. Down's syndrome and atherosclerosis. Atherosclerosis 1989; 76(2-3): 269-272.

7. Wiggins J, Hearn G, Skinner C. Recent experience in the control and management of tuberculosis in a mental handicap hospital. Respir Med 1989; 83(4): 315-319.

8. Cocchi G, Mastrocola M, Capelli M, Bastelli A, Vitali F, Corvaglia L. Immunological patterns in young children with Down syndrome: is there a temporal trend? Acta Paediatr 2007; 96(10): 1479-1482.

9. Guazzarotti L, Trabattoni D, Castelletti E, Boldrighini B, Piacentini L, Duca P, Beretta S, Pacei M, Caprio C, Vigan Ago A, di Natale B, Zuccotti $\mathrm{GV}$, Clerici M. T lymphocyte maturation is impaired in healthy young individuals carrying trisomy 21 (Down syndrome). Am J Intellect Dev Disab 2009; 114(2): 100-109.

10. Ali A, Hassiotis A. Illness in people with intellectual disabilities. BMJ 2008; 336(7644): 570-571.

11. Polat KY, Aydinli B, Yilmaz O, Aslan S, Gursan N, Ozturk G, Onbas O. Intestinal tuberculosis and secondary liver abscess. Mt Sinai J Med 2006; 73(6): 887-890.

12. Ozkaya O, Paksu MS, Bek K, Yildiz L, Fişgin T, Gürmen N, Karagöz F. Renal amyloidosis due to pulmonary tuberculosis in a patient with Down syndrome. Eur J Pediatr 2006; 165(2): 134-135.

13. Yoshida N, Takahashi Y, Mori M, Saitou K, Yokota S, Mathuyama S, Sugita A. A child case of Down's syndrome with intestinal tuberculosis and tuberculous pleuritis (in Japanese). Kansenshogaku Zasshi. 1989; 63(12): 1333-1337.

14. Ulloa R, Avila ML, Soto M, Paris MM, Faingezicht I, Odio C, Carranza A. Laryngeal tuber- culosis. Pediatr Infect Dis J 1998; 17(8): 758-760.

15. Davies PD. Risk factors for tuberculosis. Monaldi Arch Chest Dis 2005; 63(1): 37-46.

16. Rieder HL. Epidemiologic Basis of Tuberculosis Control, 1st ed. Paris: International Union Against Tuberculosis and Lung Disease, 1999.

17. Global tuberculosis control: surveillance, planning, financing. WHO report 2007. Geneva: World Health Organization, 2008.

18. Pesut D. Active case detection for tuberculosis in risk groups in Serbia (in Serbian). Med Pregl 2004; 57(Suppl 1): 75-80.

19. Chang KC, Leung CC,Yew WW, C.M. Tam CM. Supervised and induced sputum among patients with smear-negative pulmonary tuberculosis. Eur Respir J 2008; 31(5): 1085-1090.

20. Owens S, Abdel-Rahman IE,Balyejusa S, Musoke P, Cooke RP, Parry CM, Coulter JB. Nasopharyngeal aspiration for diagnosis of pulmonary tuberculosis. Arch Dis Child 2007; 92(8): 693-696.

21. Pesut D. Contemporary status of BCG vaccine in the world and in Serbia (in Serbian). Med Pregl 2004; 57(Suppl 1): 37-40.

22. Tostmann A, Kik SV, Kalisvaart NA, Sebek MM, Verver S, Boeree MJ, van Soolingen D. Tuberculosis transmission by patients with smearnegative pulmonary tuberculosis in a large cohort in The Netherlands. Clin Infect Dis 2008; 47(9): 11351142.

23. Bothamley GH, Ditiu L, Migliori GB, Lange C, TBNET contributors. Active case-finding of tuberculosis in Europe. A TBNET (Tuberculosis Network European Trials Group) survey. Eur Respir J 2008; 32(4): 1023-1030.

24. World Health Organization. Guidelines for the programmatic management of drug-resistant tuberculosis. WHO/HTM/TB/2006.361. Geneva, World Health Organization, 2006. 